\title{
Bir Üniversite Hastanesinde Çalışan Hemşirelerin Tükenmişlik Düzeyi ve Etkileyen Faktörler
}

\author{
Burnout Levels and Affecting Factors in Nurses Working in a University Hospital
}

\author{
Serkan Özsoylu, Başak Akyıldız, Adem Dursun \\ Erciyes Üniversitesi Tıp Fakültesi, Mustafa Eraslan ve Fevzi Mercan Çocuk Hastanesi, Çocuk Yoğun Bakımı Ünitesi, Kayseri, Türkiye
}

\section{Öz}

Amaç: Bir üniversite çocuk hastanesinde çalışan hemşirelerin tükenmişlik düzeyini ve ilişkili faktörleri belirlemek amacıyla gerçekleştirilmiştir.

Yöntemler: Araştırma, Nisan-Mayıs 2017 tarihleri arasında Erciyes Üniversitesi Tıp Fakültesi Çocuk Hastanesi'nde çalışan hemşireler arasında Maslach Tükenmişlik Ölçeği, Kısa Form-36 Yaşam Kalitesi Formu kullanılarak kesitsel bir çalışma şeklinde tasarlanmıştır.

Bulgular: Çalışmaya katılan 44 hemşirenin 14'ü $(\% 31,8)$ çocuk yoğun bakım ünitesinde (ÇYBÜ), geri kalan 30'u $(\% 68,2)$ ise diğer bölümlerde (servis ve poliklinik) çalışmaktaydı. \%31,8'i 25-29 yaş, \%31,8'i 30-34 yaş, \%13,6'sı 35-39 yaş ve \%22,8'i z40 yaşındaydı.

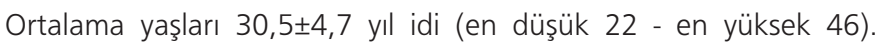
Servis hemşirelerinin emosyonel rol güçlüğü skorları yoğun bakım hemşirelerine göre belirgin yüksekti $(p=0,039)$. Aynı zamanda yoğun bakım hemşireleri sosyal işlevsellik yönünden de servis hemşirelerine göre daha iyi durumda olduğu tespit edildi $(p=0,049)$. Yoğun bakım ünitesinde çalışmak kişisel başarıda azalmayı 2,13 kat [odds oranı (OR) 2,13, \%95, güven aralığı (GA) 1,21-3,84] arttırırken, duyarsızlaşmayı 1,8 kat (OR 1,8, \%95, GA 1,07-3,34) arttırdığı tespit edildi. Çoğul lojistik regresyon analizi ile yoğun bakım ünitesinde çalışmak yine kişisel başarıda azalmayı 2,07 kat (OR 2,07; \%95, GA 1,17-3,74) arttıırken duyarsızlaşmayı, 1,76 kat (OR 1,76, \%95, GA 1,12-3,21) arttırdığı tespit edildi.

Sonuç: Yoğun bakım ünitelerinde çalışan hemşireler gerek stresli iş ortamı gerekse de yoğun çalışma temposu nedeniyle tükenmişlik sendromu açısından en riskli çalışan gruplarından birisidir. Bu nedenle ÇYBÜ hemşirelerinin belli aralıklarla değerlendirilip, elde edilen sonuçlara göre çalışma koşullarının iyileştirilmesi ve tükenmişlik sendromuyla baş etme yöntemleri konusunda eğitim verilmesi önerilebilir.

Anahtar Kelimeler: Yoğun bakım, tükenmişlik, hemşire

\section{Abstract}

Introduction: It was aimed to determine the burnout level and associated factors in nurses working in a university hospital.

Methods: The study was designed as a cross-sectional study. The Maslach Burnout Inventory, 36-Item Short-Form Health Survey were used to assess the level of burnout in nurses working in Erciyes University Faculty of Medicine between April 2017 and May 2017.

Results: A total of 44 nurses with the mean age of 30.5 years (range: 22-46) participated in the study. Fourteen (31.8\%) were working in the pediatric intensive care unit (PICU) and the remaining $30(68.2 \%)$ were working in other departments. $31.8 \%$ were in the age group $25-29,31.8 \%$ in the age group $30-34$, and $13.6 \%$ in the age group $35-39$ and, $22.8 \%$ of participants were $\geq 40$ years of age. Nurses working in the other departments had higher scores on SF36 role limitations due to emotional problems scale than PICU nurses $(p=0.039)$. At the same time, PICU nurses were also better in terms of social functioning than nurses working in other departments $(p=0.049)$. It was observed that working in intensive care unit decreased personal goal achievement [odds ratio (OR) 2.13,95\%, confidence interval $(\mathrm{Cl})$ 1.21-3.84] 2.13 times and increased depersonalization (OR 1.8, 95\%, Cl 1.07-3.34) 1.8 times. In multiple regression analysis, it was found that working in intensive care unit decreased personal goal achievement (OR 2.07, 95\%, Cl 1.17-3.74) 2.07 times and increased depersonalization (OR 1.76, 95\%, Cl 1.123.21) 1.76 times.

Conclusion: Nurses working in intensive care units constitute one of the highest risk groups for burnout syndrome due to stressful working conditions as well as intense work environment. For this reason, assessment of burnout in PICU nurses at certain intervals and based on the results obtained, improving working conditions besides providing coping skills training may be suggested.

Keywords: Intensive care, burnout, nurse

Yazışma Adresi/Address for Correspondence: Dr. Serkan Özsoylu, Erciyes Üniversitesi Tıp Fakültesi, Mustafa Eraslan ve Fevzi Mercan Çocuk Hastanesi, Çocuk Yoğun Bakımı Ünitesi, Kayseri, Türkiye E-posta: sozsoylu@hotmail.com ORCID ID: orcid.org/0000-0002-2315-5027

Geliş Tarihi/Received: 01.11.2017 Kabul Tarihi/Accepted: 15.11.2017

๑Telif Hakkı 2017 Çocuk Acil Tıp ve Yoğun Bakım Derneği

Çocuk Acil ve Yoğun Bakım Dergisi, Galenos Yayınevi tarafından basıımıştır. 


\section{Giriş}

Tükenmişlik sendromu (TS) çalısma ortamındaki süreğen stresin eşlik ettiği duygusal tükenme (DT), depersonalizasyon ve mesleki başarının azalması ile karakterize bir tablodur. ${ }^{1}$ DT enerji eksikliği ve mesleki motivasyon eksikliği ile karakterize edilen, genellikle ilişkilerdeki kişisel çatışmalar ve ağır iş yükünden kaynaklanan bir durumdur. Depersonalizasyon, duygusal ayrışmanın psikolojik bir halidir. İşyerindeki çalışma arkadaşlarının tutumuna bağlı olarak anksiyete, irritabilite ve demotivasyon gelişir. Modern yaşamın mesleki alanı içinde uzun süredir büyük bir sorun olarak kabul edilmiştir ve son on yılda çok daha yaygın hale gelmiştir. ${ }^{2}$ Bu fenomen, sağlık hizmet sunucularında yalnızca işin doğası nedeniyle değil, aynı zamanda yüksek görülme oranı nedeniyle de özel bir öneme sahiptir. Sağlık profesyonellerinde bu sendrom uzun süredir yaygın olmasına rağmen, çalışmalar sadece neden-sonuç ilişkilerini ve önleyici önlemleri değerlendirmek için yapılmışır. ${ }^{3}$ Sağlık çalışanları arasında TS yaygınlığı ve sıklığı hakkında mevcut literatürde bir görüş birliği bulunmamaktadır. ${ }^{4,5}$ Yoğun bakım ünitelerinde sağlık uzmanları arasında yapılan çalışmalarda tükenmişlik oranları \%0-70 arasında değişmektedir. ${ }^{6}$

Son yıllarda çocuk yoğun bakımı alanındaki gelişmeler, ileri yaşam desteğindeki ilerlemeler ve gelişmiş hemşire bakımı sonucunda artmış beklenti ve zor çalışma koşulları stresli bir ortam yaratmaktadır. Bu ortamdan en çok etkilenen meslek gruplarından birisi de hemşirelerdir. Ağır iş yükü, zaman baskısı, ileri yaşam desteğinin yoğun kullanımına rağmen sonuçların her zaman yüz güldürücü olmaması hemşirelerde fiziksel ve duygusal zorlanmalara neden olmaktadır. ${ }^{1}$ Yakın zamana kadar, yoğun bakım topluluğu stresli yoğun bakım ünitesi ortamında, TS'nin gelişimi ve diğer psikolojik rahatsızlıklar gibi zararlı etkilerden nispeten habersizdi. ${ }^{1,7-9} \mathrm{Ne}$ yazık ki, kritik bakımda görevli sağlık çalışanları en yüksek TS oranlarından birine sahiptir. Bu bozukluğun gelişimi hastalara doğru yaklaşımda bulunma kabiliyetini olumsuz yönde etkileyebilir. ${ }^{10}$

Bu çalışmada hastanemiz çocuk yoğun bakımı ünitesi ve diğer çocuk sağlığı ve hastalıkları servislerinde çalışan hemşirelerde tükenmişlik durumunu analiz etmek ve ilişkili faktörleri belirlemeyi amaçladık.

\section{Gereç ve Yöntem}

Kesitsel tipte yapılan bu araştırma Erciyes Üniversitesi Tıp Fakültesi, Çocuk Hastanesi'nde Nisan-Mayıs 2017 tarihleri arasında yapılmış olup toplam 177 hemşire çalışma grubunu oluşturdu. Örneklem seçimine gidilmeyip evrenin tamamına ulaşılması hedeflendi. Yüz yetmiş yedi hemşireden 44'ü çalışmaya katılmayı kabul etti. Çalışmaya katıım oranı $\% 24,8$ idi. Bu araştırmada veri toplama aracı olarak "Sosyo-demografik

\section{Tablo 1. Sosyo-demografik veri formu}

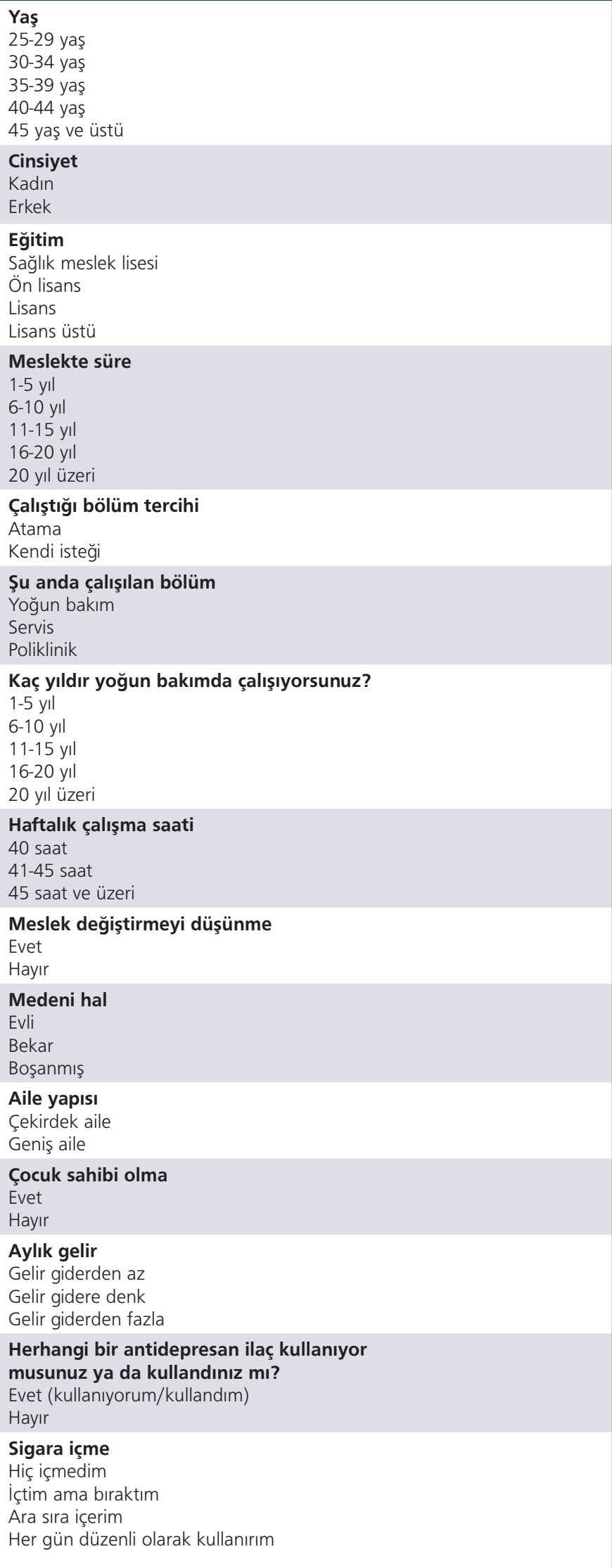




\section{Tablo 1 'in devam}

\section{Alkol kullanımı}

Hiç

içmedim

içtim ama bıraktım

Ara sıra içerim

Her gün düzenli olarak kullanırım

Sosyal etkinlik

Var

Yok

Tatil yapma sıklığı

Hiç yapmıyorum

Haftasonları

Ayda bir

Yaz tatili

Yılda iki hafta

\section{İşyerine ulaşım}

Yürüyerek

Toplu taşıma

Kendi arabası

iş yeri servisi

Veri Toplama Formu" (Tablo 1), "Maslach Tükenmişlik Ölçeği" ve "Kısa Form (KF)-36 Yaşam Kalitesi Formu" kullanıldı. Çalışma, Erciyes Üniversitesi Tıp Fakültesi Etik Kurulu (tarih: 07/04/2017 karar no: 2017/190) tarafından onaylandı. Çalışmaya katılan hemşirelerden yazılı bilgilendirilmiş onam alındı.

\section{Maslach Tükenmişlik Ölçeği}

Maslach ve Jackson (1981) tarafından geliştirilen ölçek, Ergin ${ }^{11}$ tarafından Türkçe'ye uyarlanmış olup Maslach Tükenmişlik Ölçeği 22 ifadeden oluşmaktadır. DT ile ilgili 9 madde, kişisel başarı (KB) ile ilgili 8 madde ve duyarsızlaşma (D) ile ilgili 5 madde bulunmaktadır. ${ }^{5}$ Araştırmamızda kullandığımız Maslach Tükenmişlik Ölçeği 5 dereceli likert bir ölçektir (0: Hiçbir zaman, 1: Çok nadir, 2: Bazen, 3: Çoğu zaman, 4: Her zaman).

Ölçeğin, Türkçe geçerlilik ve güvenirlik çalışmasında alt ölçeklerin Cronbach alfa değerleri DT boyutu için 0,90, D boyutu için $0,79, K B^{\prime}$ de düşme boyutu için 0,71 olduğu belirtilmektedir. ${ }^{11}$

DT için 1., 2., 3., 6., 8., 13., 14., 16., 20. sorular puanlandırılarak; 0-11 puan arası düşük, 12-17 puan arası orta, 18 ve üzeri puan yüksek risk olarak sınıflandırıldı.

D için 5., 10., 11., 15., 20., 22. sorular puanlandırlarak; 0-5 puan arası düşük, 6-9 puan arası orta risk ve 10 ve üzeri puan yüksek risk olarak sınıflandırıldı.

KB'de azalma için 4., 7., 9., 12., 17., 18., 19., 21. sorular değerlendirildi. Çalışmamızda, KB için de düz puanlama yapılmış olup, KB için 0-21 puan yüksek, 22-25 puan arası orta, 26 ve üzeri puan düşük risk olarak kabul edildi.

\section{Kısa Form-36 Yaşam Kalitesi Ölçeği}

Ölçek 36 madde ve 8 alt boyuttan oluşmaktadır. Fiziksel işlevi, ağrı, genel sağlık, enerji durumu, sosyal işlev, zihinsel durum rolünü ve zihinsel sağlık durumunu değerlendiren parametrelerden oluşur. Alt ölçeklerle sağlığı 0-100 arasında değerlendirir ve 0 kötü sağlık durumunu, 100 iyi sağık durumunu gösterir. Rand Corporation tarafından 1992 ylında geliştirilmiş olan ölçeğin Türkçe geçerlik ve güvenirlik çalışması Koçyiğit ve ark. ${ }^{12}$ tarafından yapılmıştır. Türkçe geçerlilik ve güvenirlik çalışmasında alt ölçeklerin Cronbach alfa değerleri 0,73-0,76 arasında bulunmuştur.

\section{İstatistiksel Analiz}

Verilerin istatistiksel analizi Statistical Package for the Social Sciences (SPSS) 22,0 paket programında yapıldı. Tüm değişkenlere öncelikle Shapiro-Wilk testi uygulanarak normal ya da anormal dağılım olup olmadığı belirlendi. Normal dağılımı olmayan değişkenler ortanca ve çeyrekler arası açıklık, kategorik değişkenler sayı (\%) olarak belirtildi. İili grupların karşılaştııımasında anormal dağııımlı değişkenler söz konusu ise Mann-Whitney $U$ testi, kategorik verilerin analizinde ise ki-kare testi kullanıldı. Parametreler arasındaki korelasyonları analiz etmek için Pearson korelasyon testi kullanıldı. Çocuk yoğun bakım ünitesinde çalışmanın Maslach Tükenmişlik Ölçeği üzerindeki etkilerini değerlendirmek için tek değişkenli ve çoğul lojistik regresyon analizleri yapılmıştır. Tüm sonuçlar için $p<0,05$ anlamlı kabul edildi.

\section{Bulgular}

Çalışmaya katılan 44 hemşirenin 14'ü $(31,8)$ çocuk yoğun bakım ünitesinde, geri kalan 30'u $(\% 68,2)$ ise diğer çocuk servislerinde çalışmaktaydı. \%31,8'i 25-29 yaş, \%31,8'i 30-34 yaş, \%13,6'sı 35-39 yaş ve \%22,8'i $\geq 40$ yaşındaydı. Ortalama yaşları 30,5 $\pm 4,7$ yıl idi (en düşük 22 - en yüksek 46). \%63,6'sı 35 yaşından küçük olmasına rağmen mesleğinde 10 yılı tamamlamışlarla, tamamlamamışların sayısı birbirine eşitti. Serviste çalışan hemşirelerin yaş ortalaması yoğun bakım ünitesinde çalışan hemşirelere oranla daha yüksekti $(p=0,023)$. Eğitim durumları incelendiğinde hemşirelerin büyük bir çoğunluğu $(\% 93,1) 4$ yıllık üniversite mezunuydu. Sadece ikisi ön lisans mezunu iken bir hemşire de yüksek lisans yapmıştı. Diğer servislerde evli hemşire oranı \%83,3'lerde iken yoğun bakım ünitesinde bu oran $\% 50$ idi $(p=0,011)$. Bu evlilik oranlarının çocuk sahibi olup olmama oranlarılla benzerlik gösterdiği saptandı. Yoğun bakım ünitesindeki hemşirelerin \%50'si çocuk sahibi iken servisteki hemşirelerde bu oran $\% 86,7$ 'ye çıkmaktaydı.

Hem yoğun bakım hem de servis hemşirelerinin \%88,7'sinde antidepresan kullanım öyküsü yoktu. Büyük bir çoğunluğu hayatlarında hiç alkol $(\% 93,1)$ veya sigara $(\% 61,3)$ tüketmemişlerdi. Yoğun bakım hemşirelerinin \%64,2'si sosyal 
etkinliklere vakit ayırabiliyorken bu oran servis hemşirelerinde $\% 46,7$ idi. Hiç tatile çıkma fırsatı bulamayan hemşirelerin oranı servislerde \%3,3, yoğun bakım ünitesinde ise $\% 17,6$ idi (Tablo 2).

KF-36 Yaşam Kalite Ölçeği alt grupları incelendiğinde servis hemşirelerinin emosyonel rol güçlüğü skorları yoğun bakım hemşirelerine göre belirgin yüksekti $(p=0,039)$. Aynı zamanda yoğun bakım hemşireleri sosyal işlevsellik yönünden de servis hemşirelerine göre daha iyi durumda oldukları belirlendi $(p=0,049)$. Ağrı skorlarına bakıldığında yoğun bakım hemşirelerinin ortanca ağrı skoru 55 (35-68) iken servis hemşirelerinin ortanca ağrı skoru 68 (45-90) olarak bulundu $(p=0,015)$ (normal dağılımı olmayan değişkenler ortanca ve çeyrekler arası açıklık [IQR] olarak belirtilmiştir). Yoğun bakım

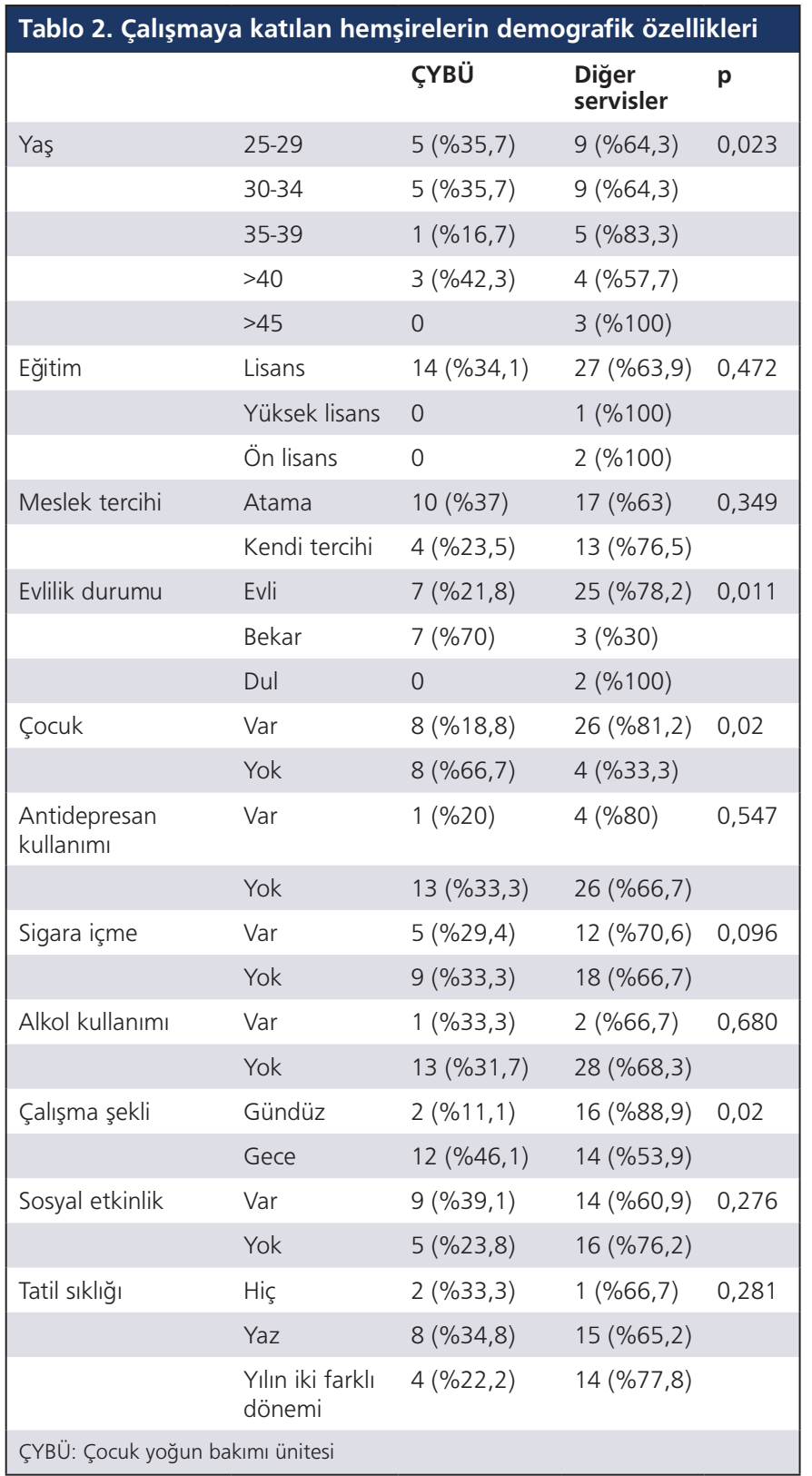

hemşireleri servis hemşirelerine göre daha enerjik olarak tespit edildi $(p=0,031)$ (Tablo 3).

Tek değişkenli lojistik regresyon analizi kullanıldığında yoğun bakım ünitesinde çalışmak KB'de azalmayı 2,13 kat [odds oranı (OR) 2,13, \%95, güven aralığı (GA) 1,21-3,84] arttıırken, D'yi 1,8 kat (OR 1,8; \%95, GA 1,07-3,34) arttırdığı tespit edilmişdi. Yoğun bakım ünitesinde çalışmanın DT üzerine istatistiksel olarak anlamlı bir etkisi saptanamadı. Çoğul lojistik regresyon analizi ile yoğun bakım ünitesinde çalısmak yine $K B^{\prime}$ de azalmayı 2,07 kat (OR 2,07, \%95, GA 1,17-3,74) arttırırken, D'yi 1,76 kat (OR 1,76, \%95, GA 1.12-3.21) (Tablo 4) arttırdığı saptandı.

\begin{tabular}{llll}
\multicolumn{4}{l}{ Tablo 3. Hemşirelerin servislere göre Kısa Form-36 skorları } \\
\hline & ÇYBÜ & Servis & p \\
Fiziksel işlev & $75(64-85)$ & $55(40-70)$ & 0,191 \\
Fiziksel rol güçlüğü & $25(0-50)$ & $50(25-57)$ & 0,075 \\
Emosyonel rol güçlüğü & $34(5-90)$ & $67(25-75)$ & 0,039 \\
Enerji & $53(25-57)$ & $45(30-53)$ & 0,031 \\
Ruhsal sağlık & $69(59-76)$ & $66(56-72)$ & 0,128 \\
Sosyal işlevsellik & $75(60-75)$ & $50(38-64)$ & 0,049 \\
Ağrı & $55(35-68)$ & $68(45-90)$ & 0,015 \\
Genel sağlık & $60(35-65)$ & $48(40-60)$ & 0,107 \\
çYBÜ: Çocuk yoğun bakım ünitesi & & & \\
\hline
\end{tabular}

Tablo 4. Cocuk yoğun bakımı ünitesinde çalışmanın tükenmişlik üzerine etkisinin lojistik regresyon analizi f̉le değerlendirilmesi

\begin{tabular}{|lllllll|} 
& \multicolumn{3}{c}{$\begin{array}{l}\text { Tek değişkenli lojistik } \\
\text { regresyon }\end{array}$} & \multicolumn{4}{c|}{ Çoğul lojistik regresyon } \\
Değişkenler & OR & $\% 95 \mathrm{GA}$ & $\mathrm{p}$ & $\mathrm{OR}$ & $\% 95 \mathrm{GA}$ & $\mathrm{p}$ \\
$\begin{array}{l}\text { Kişisel } \\
\text { başarıda } \\
\text { azalma }\end{array}$ & 2,13 & $1,21-3,84$ & 0,009 & 2,07 & $1,17-3,74$ & 0,001 \\
$\begin{array}{l}\text { Duygusal } \\
\text { tükenmişlik }\end{array}$ & 1,04 & $0,87-1,25$ & 0,633 & & & \\
$\begin{array}{l}\text { Duyarsızlaşma } \\
\text { OR: Odds oranı, GA: Güven aralığı }\end{array}$ & 1,8 & $1,07-3,34$ & 0,025 & 1,76 & $1,12-3,21$ & 0,017 \\
\hline
\end{tabular}

\section{Tartışma}

Literatürde tükenmişliğin hemen her meslek grubunda yaşandığı belirtilmekle birlikte özellikle sağlık çalışanları gibi birebir insan ilişkileri üzerinden yürüyen mesleklerde daha fazla yaşandığı belirtilmektedir. ${ }^{13,14}$ Güneş ve Üstün ${ }^{15}$ yaptıkları bir çalışmada değişik üniversite hastanelerinden seçmiş oldukları sağlık çalışanlarında tükenmişliğin yoğun yaşandığını saptamışlardır. Bu çalışmada yoğun bakımda çalışan hemşirelerin tükenmişlik oranları \%57'leri bulurken, servis hemşirelerinde bu oran $\% 38^{\prime}$ lerdeydi. Hastane geneline baktığımızda ise yaklaşık iki hemşireden biri (\%47) kendini 
tükenmiş olarak ifade etmekteydi. Literatüre bakıldığında yoğun bakım ünitelerinde çalışan sağlık uzmanları arasında tükenmişlik oranları \%70'lere kadar çıkabilmektedir. ${ }^{6}$ Oehler ve Davidson ${ }^{16}$ Çocuk yoğun bakımı ünitelerinde hemşireler arasında yaptığı bir çalışmada tükenmişlik oranı $\% 66$ olarak saptanmıştır.

Maslach yaşın TS açısından bir risk faktörü olmadığını belirtmiştir. ${ }^{17}$ Onun söylediklerinin aksine, yapılan bir metaanalize göre genç yaşta olanlar ve deneyimi az olan çalışanların tükenmişlik oranlarının daha fazla olduğu saptanmışıı..18 Yoğun bakımdaki hemşirelerin iş yükünün yanı sıra, genellikle yoğun bakıma verilen/atanan hemşirelerin genç ve deneyimsiz olmalarının çalışmamızda bulduğumuz sonuçlarla ilişkili olduğunu düşünmekteyiz. Literatür incelendiğinde, bu çalışmaya paralel olarak yaş ilerledikçe KB puanlarının yükseldiği görülmektedir. ${ }^{19}$ Meslekte geçirilen süre arttıkça, KB puanları da artmaktadır. Yaşla birlikte her meslekte olduğu gibi hemşirelerin de sorunların üzerinden gelme yetileri gelişmekte ve bundan dolayı hemşirelerin kendilerini daha başarılı buldukları yorumu yapılabilir.

Yoğun bakım hemşirelerinin Maslach Tükenmişlik Ölçeği alt boyutlarının dağılımına baktığımızda; hemşirelerin en fazla KB'de azalma ve D'yi yaşadıkları saptanmıştır. Çocuk yoğun bakımı ünitelerinde yapılan bir çalışmada \%32 oranıyla KB'de azalma en sık gözlenirken, çalışmamızla uyumlu olarak ikinci sırayı \%24 oranıyla "D" almıştır. ${ }^{16}$ Tek değişkenli lojistik regresyon analizi kullanıldığında yoğun bakımı ünitesinde çalışmak bağımsız olarak KB'yi 2,13 kat azaltmakta, D'yi de 1,8 kat arttırmaktaydı. Çoğul lojistik regresyon analizi ile yoğun bakımı ünitesinde çalışmak yine KB'de 2,07 kat bir azalmaya neden olurken, D'de de 1,76 kat bir artışa neden olmuştu. Elde edilen bulgular literatürle farklılık göstermektedir. Altay ve ark. ${ }^{20}$ yaptığı bir çalışmada hemşirelerin en fazla KB'de azalmayı ve DT'yi yaşadığı, en az ise D'yi yaşadığını saptamışlardır. Metin ve Özer ${ }^{21}$ ve Ergin ve ark. ${ }^{22}$ ise hemşirelerin DT ve KB'de azalmayı en fazla yaşadıklarını belirtmişlerdir. Maslach, D'yi karşısındaki insana duygudan yoksun davranış sergilenmesi olarak tanımlamıştır. Bireyleri nesne olarak görüp, onlara nesne gibi davranırlar. Kendini yetersiz görme, işe karşı motivasyon düşüklüğü, kontrol eksikliği ve çaresizlik hissi ise $\mathrm{KB}$ eksikliğidir. ${ }^{16} \mathrm{D}^{\prime}$ deki bu farkııı̆ın yoğun bakım hemşirelerinin ilgilendiği hastaların daha zor ve daha kötü durumlardaki hastalar olmasından kaynaklandığını düşünmekteyiz. Bunun yanında yoğun bakım hastalarındaki mortalite oranı da yüksek olduğundan, yoğun bakım hemşireleri kendilerini yetersiz görebilmekte ve çaresiz hissetmektedirler. Bu durum da KB'lerinde azalmaya yol açmaktadır.

KF-36 yaşam kalitesi ölçeği alt grupları incelendiğinde yoğun bakım hemşireleri sosyal işlevsellik yönünden de servis hemşirelerine göre daha iyi durumdaydılar. Ağrı skorlarına bakıldığında yoğun bakım hemşirelerinin ortanca ağı skoru 55 (35-68) iken servis hemşirelerinin ortanca ağrı skoru 68 (45-90) olarak bulundu $(p=0,015)$ (normal dağılımı olmayan değişkenler ortanca ve çeyrekler arası açıklık [IQR] olarak belirtilmiştir). Bu kadar yoğun bir tempoda çalışmalarına rağmen yoğun bakım hemşireleri servis hemşirelerine göre daha enerjikti. Biz bu üç parametrenin de yoğun bakımda çalışan hemşirelerin daha genç olmasına bağladık. Özellikle ağrı skorunun servis hemşirelerinde yüksek olmasının bir nedeni de yaşla beraber artmakta olan süreğen hastalığa sahip olma riskiyle ilişkilendirdik.

\section{Sonuç}

Sonuç olarak yoğun bakımı ünitelerinde çalışan hemşireler gerek stresli iş ortamı gerekse de yoğun çalışma temposu nedeniyle TS açısından en riskli çalışan gruplarından birisidir. Özellikle Maslach Tükenmişlik alt ölçeklerinden KB'de azalma ve D'de diğer servis hemşirelerine göre daha kötü durumda olmaları yoğun bakım hemşirelerinin kendine olan güvenlerini azaltmakta ve mesleki motivasyonlarını düşürmektedir. Bu nedenle yoğun bakım hemşirelerinin çalışma koşulları gözden geçirilerek, mesleki motivasyonlarının artması için neler yapılabileceği hususunda gerekli adımlar atılmalıdır.

\section{Etik}

Etik Kurul Onayı: Erciyes Üniversitesi Tıp Fakültesi Etik Kurulu'ndan (tarih: 07/04/2017 karar no: 2017/190) onay alınmıştır.

Katılımcı Onayı: Çalışmaya katılan tüm hemşirelerden onam alınmıştır.

Hakem Değerlendirmesi: Editörler kurulu dışında olan kişiler tarafından değerlendirilmiştir.

\section{Yazarlık Katkıları}

Konsept: S.Ö., Dizayn: S.Ö., Veri Toplama veya Işleme: S.Ö., A.D., Analiz veya Yorumlama: S.Ö., B.A., Literatür Arama: S.Ö, A.D., Yazan: S.Ö.

Çıkar Çatışması: Yazarlar tarafından çıkar çatışması bildirilmemiştir.

Finansal Destek: Yazarlar tarafından finansal destek almadıkları bildirilmiştir

\section{Kaynaklar}

1. Mealer ML, Shelton A, Berg B, Rothbaum B, Moss M. Increased prevalence of post-traumatic stress disorder symptoms in critical care nurses. Am J Respir Crit Care Med. 2007;175:693-7.

2. Vander Elst T, Cavents C, Daneels K, Johannik K, Baillien E, et al. Job demands-resources predicting burnout and work engagement among Belgian home health care nurses: A cross-sectional study. Nurs Outlook. 2016;64:542-56. 
3. Gazelle G, Liebschutz JM, Riess H. Physician burnout: coaching a way out. J Gen Intern Med. 2015;30:508-13.

4. Angelo RP, Chambel MJ. The reciprocal relationship between workcharacteristics and employee burnout and engagement: a longitudinal study of firefighters. Stress Health. 2015;31:106-14.

5. Balch CM, Shanafelt T. Combating stress and burnout in surgical practice: a review. Thorac Surg Clin. 2011;21:417-30.

6. van Mol MM, Kompanje EJ, Benoit DD, Bakker J, Nijkamp MD. The prevalence of compassion fatigue and burnout among healthcare professionals in intensive care units: a systematic review. PLoS One. 2015; 10:e0136955

7. Azoulay E, Herridge M. Understanding ICU staff burnout: the show must go on. Am J Respir Crit Care Med. 2011;184:1099-100.

8. Chlan LL. Burnout syndrome among critical care professionals: a cause for alarm. Critical Care Alert. 2013;21:65-8.

9. Embriaco N, Papazian L, Kentish-Barnes N, Pochard F, Azoulay E. Burnout syndrome among critical care healthcare workers. Curr Opin Crit Care. 2007;13:482-8.

10. Peckham C. Medscape physician lifestyle report 2015. http:// www.medscape.com/features /slideshow/lifestyle/2015/public/ overview\#1. Accessed January 26,2015.

11. Ergin C. Doktor ve hemşirelerde tükenmişlik ve Maslach Tükenmişlik Ölçeğinin uyarlanması. İçinde: Bayraktar R, Dağ D. VII. Ulusal Psikoloji Kongresi Çalışmaları, 22-25 Eylül 1992, Ankara: Türk Psikologlar Derneği Yayını, 1993:143-54.

12. Koçyiğit H, Aydemir Ö, Fişek G, Ölmez N, Memiş A. Kısa Form36'nın Türkçe Versiyonunun Güvenilirliği ve Geçerliliği. İlaç ve Tedavi Dergisi. 1999;12:102-6.
13. Kowalski C, Ommen O, Driller E, Ernstmann N, Wirtz M, et al. Burnout in nurses - the relationship between social capital in hospitals and emotional exhaustion. J Clin Nurs. 2010;19:1654-63.

14. Gustafson G, Eriksson S, Strangberg G, Norberg A. Burnout and perceptions of conscience among healthcare personel: a pilot study. Nursing Ethics. 2010;17:23-38.

15. Güneş N, Üstün B. Bir üniversite hastanesinde çalışan hemşirelerin tükenmişlik düzeyi ve etkileyen faktörlerin incelenmesi. Anadolu Hemşirelik ve Sağlık Bilimleri Dergisi. 2008;11:48-58.

16. Oehler JM, Davidson MG. Job stress and burnout in acute and nonacute pediatric nurses. Am J Crit Care. 1992;1:81-90.

17. Maslach C, Schaufeli WB, Leiter MP. Job burnout. Annu Rev Psychol. 2001;52:397-422.

18. Brewer EW, Shapard L. Employee burnout: A meta-analysis of the relationship between age or years of experience. Human Resource Development Review. 2004;3:102-23.

19. Taycan O, Kutlu L, Cimen S, Aydın N. Bir Üniversite Hastanesinde Çalışan Hemşirelerde Depresyon ve Tükenmişlik Düzeyinin Sosyodemografik Özelliklerle olan ilişkisi. Anadolu Psikiyatri Derg. 2006;7:100-8.

20. Altay B, Gönerer D, Demirkıran C. Bir üniversite hastanesinde çalışan hemşirelerin tükenmişlik düzeyleri ve aile desteğinin etkisi. Firat Tıp Dergisi. 2010;15:10-6.

21. Metin Ö, Özer G. Hemşirelerin tükenmişlik düzeylerinin belirlenmesi, Atatürk Üniversitesi Hemşirelik Yüksekokulu Dergisi. 2007:10:1

22. Ergin D, Şen N, Akış Ş, Altan Ö, Bakırlıoğlu Ö, ve ark. Dahili Kliniklerde Görev Yapan Hemşirelerin Tükenme ve Empatik Beceri Düzeyleri ve Bunları Etkileyen Faktörlerin Belirlenmesi, Fırat Sağlık Hizmetleri Dergisi. 2009;4:50-63. 